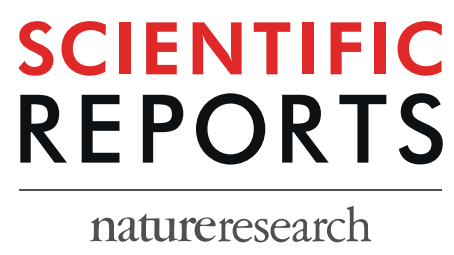

\title{
OPEN Agro-industrial by-product in photoheterotrophic and mixotrophic culture of Tetradesmus obliquus: Production of $\omega 3$ and $\omega 6$ essential fatty acids with biotechnological importance
}

\begin{abstract}
Agata Piasecka*, Agnieszka Nawrocka, Dariusz Wiącek \& Izabela Krzemińska
In recent years, researchers have highlighted the role of low cost-efficient agro-industrial by-products used as supplements in algal culture media. The aim of the study was to identify and characterize the basic metabolic pathways in Tetradesmus obliquus cells induced by supplementation with beet molasses in photoheterotrophic and mixotrophic culture conditions. To assess the impact of the nutritional strategy in unicellular algae, growth curves were plotted and lipid, carbohydrate, and protein levels were determined. Fourier Transform Infrared Spectroscopy was applied to measure the Tetradesmus obliquus cell composition. Additionally, the C16-C18 fatty acid profile of Tetradesmus obliquus was determined by gas chromatograph/mass spectrometry. The switch from autotrophy to photoheterotrophy and mixotrophy contributes to shortening of the adaptation growth phase. The highest protein content was obtained in the mixotrophic growth. This study has demonstrated high content of 18:1, cis $\Delta_{9,}, 18: 2, \operatorname{cis} \Delta_{9,12}, \omega 6$, and 18:3, cis $\Delta_{9,12,15}, \omega 3$ in photoheterotrophic and mixotrophic culture conditions. High levels of proteins and essential fatty acids make Tetradesmus obliquus cell biomass important for human and animals health.
\end{abstract}

Microalgae are not only a source of many valuable bio-products e.g. proteins, carbohydrates, lipids, $\omega 3$ and $\omega 6$ fatty acids or pigments applied in many different commercial sectors but can be a simple and economical solution to wastewater treatment and waste management ${ }^{1}$. Algal cells utilize effectively agricultural, industrial and municipal wastewaters, waste raw materials, and by-products from many branches of industry. Algae are capable of assimilating organic compounds and other ingredients for biomass production and synthesis of both basic and specific metabolites. Additionally, the use of wastewaters and waste materials make microalgal biomass and bio-product production environmentally friendly ${ }^{2}$. A number of studies have described supplementation of the algal culture medium with agricultural waste such as dairy manure ${ }^{3}$, liquid waste produced in piggeries ${ }^{4}$, post-fermentation effluents and wastewater from fruit, vegetable or cultivated plant processing, i.e. residues of cane bagasse and pineapple peel ${ }^{5}$, cassava ${ }^{6}$, sweet sorghum ${ }^{7}$, or hydrolysate of Jerusalem artichoke tubers ${ }^{8}$.

Most algae are autotrophs; however, some species such as Auxenochlorella protothecoides ${ }^{9}$ Parachlorella kessler ${ }^{10}$ and Tetradesmus obliquus can assimilate organic compounds. Cultivation modes based on organic carbon sources include heterotrophy, photoheterotrophy, and mixotrophy ${ }^{11}$. Compared to the heterotrophic mode, the photoheterotrophic and mixotrophic cultivation systems have several advantages e.g. intensification of algal growth and synthesis of valuable metabolites, such as fatty acids ${ }^{12}$. Green algae growing in photoheterotrophic and mixotrophic culture conditions are natural producers of polyunsaturated fatty acids ${ }^{10,13}$. In terms of human nutrition, one of the most important PUFAs are essential fatty acids including short chain polyunsaturated fatty acids: $\omega 3$ ( $\alpha$-linolenic acid; 18:3, cis $\Delta_{9,12,15}$ (ALA)) and $\omega 6$ (linoleic acid; 18:2, cis $\Delta_{9,12}$ (LA)), which are precursors 


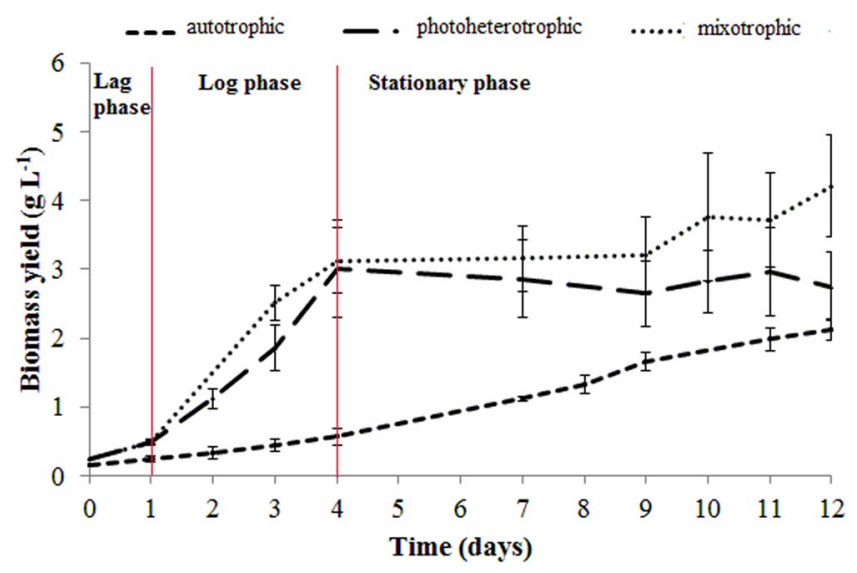

Figure 1. Growth curve of Tetradesmus obliquus under autotrophic, photoheterotrophic, and mixotrophic culture conditions with marked growth phases; lag, log, and stationary (the results are presented as the means of 9 measurements from three biological replicates, error bars represent SD).

for formation of long chain polyunsaturated fatty acids but cannot be synthesized by humans ${ }^{14-16}$. Besides application in human and animal nutrition, fatty acids are used in production of biofuels ${ }^{17}$. The similarity of the photoheterotrophic cultivation system to mixotrophy consists in microalgal requirements for light and the utilization of organic compounds as a carbon source. In contrast to mixotrophy, microalgae cultivated in photoheterotrophic culture conditions cannot absorb carbon dioxide ${ }^{11}$. Photoheterotrophy is very rarely applied in comparison with mixotrophic cultivation.

Tetradesmus obliquus (Scenedesmus obliquus) is considered as a suitable candidate for utilization of organic carbon sources of agricultural origin in mixotrophic culture conditions, especially in biodiesel production ${ }^{17}$. In turn, the photoheterotrophic cultivation of T. obliquus is a yet unknown area. To the best of our knowledge, this is the first study to examine the potential of beet molasses application in the production of $\omega 3$ and $\omega 6$ essential fatty acids.

The aim of this study is to identify and characterize the basic metabolic pathways in unicellular green algae T. obliquus induced by supplementation with beet molasses as a source of carbon and nitrogen. The study investigates the effect of autotrophic, photoheterotrophic, and mixotrophic culture conditions on growth parameters and biochemical composition with special consideration of the C16-18 fatty acid profile in T. obliquus cells.

\section{Results}

Growth characteristics of T. obliquus. The T. obliquus growth depending on the culture conditions is presented in Fig. 1. Three culture variants were used, i.e. autotrophic, photoheterotrophic, and mixotrophic, which corresponded to the aerated culture (control), molasses-supplemented culture, and aerated molasses-supplemented culture. The algal growth on the liquid medium was illustrated graphically as growth curves. The analysis of the curves indicated the individual growth phases. The course of the growth curves depends on the conditions used in the experiment. A linear phase was observed in the autotrophic culture. In the photoheterotrophic culture, there was a short lag phase (0-1 day) followed by a log phase (1-4 days) and a stationary phase (4-12 days). As in the photoheterotropic culture, the mixotrophic variant was characterised by a short lag phase (0-1 day) and a log phase (1-4 days). The mixotrophic culture growth declined, but no typical stationary phase was noted.

The growth conditions exert a significant effect on the biomass yield, daily biomass productivity, and growth parameters in T. obliquus, i.e. the specific growth rate ( $0-3$ days) and the biomass doubling time $(0-72 \mathrm{~h})$. Table 1 presents all parameters of T. obliquus growth. In the autotrophic variant, $2.12 \mathrm{~g} \mathrm{~L}^{-1}$ of T. obliquus cell biomass were obtained after 12 days of cultivation. The highest increase in T. obliquus biomass, i.e. $4.21 \mathrm{~g} \mathrm{~L}^{-1}$, was noted in the mixotrophic culture. Simultaneously, the level of daily biomass productivity was estimated at $0.39 \mathrm{gL}^{-1} \mathrm{day}^{-1}$. The specific growth rate in T. obliquus increased in the following order: autotrophic $<$ photoheterotrophic $<$ mixotrophic. The T. obliquus biomass doubling time in the control culture was over $51 \mathrm{~h}$ and 2.4 -fold shorter in the mixotrophic culture.

Analysis of T. obliquus biomass by Fourier Transform Infrared Spectroscopy. The results of the FT-IR spectra in the range from 800 to $1800 \mathrm{~cm}^{-1}$ and from 2400 to $3600 \mathrm{~cm}^{-1}$ are shown in Fig. 2a,b. Table 2 shows the location of the maximum of absorption bands of all T. obliquus cells. In the analysed range of 600$4000 \mathrm{~cm}^{-1}$, there are typical absorption bands characteristic for three main macromolecules: proteins, lipids, and carbohydrates. There is a carbohydrate band located in the range of $900-1200 \mathrm{~cm}^{-1}$, lipid bands with maximum absorption at ca. $1735 \mathrm{~cm}^{-1}$ and $2917 \mathrm{~cm}^{-1}$, and amide I and amide II bands in a protein region at ca. $1640 \mathrm{~cm}^{-1}$ and $1540 \mathrm{~cm}^{-1}$.

The spectra (Fig. 2a), show a band in the wavenumber range of $900-1200 \mathrm{~cm}^{-1}$ with a maximum at ca. $1025 \mathrm{~cm}^{-1}$ assigned to stretching vibrations of C-O-C functional groups typical of carbohydrates and at a maximum of ca. $1150 \mathrm{~cm}^{-1}$ assigned to stretching vibrations of $\mathrm{C}-\mathrm{O}-\mathrm{C}$ functional groups. The band appearing in the spectra with a maximum at ca. $1240 \mathrm{~cm}^{-1}$ was assigned to asymmetrical stretching vibrations of the $\mathrm{P}=\mathrm{O}$ bond located in the phosphodiester groups of nucleic acids and phospholipids. 


\begin{tabular}{|c|c|c|c|}
\hline & \multicolumn{3}{|c|}{ Tetradesmus obliquus } \\
\hline & autotrophy & photoheterotrophy & mixotrophy \\
\hline & \multicolumn{3}{|c|}{ Growth parameters* } \\
\hline Biomass yield $\left(\mathrm{g} \mathrm{L}^{-1}\right)$ & $2.12 \pm 0.15^{\mathrm{a}}$ & $2.86 \pm 0.56^{\mathrm{a}}$ & $4.21 \pm 0.74^{\mathrm{b}}$ \\
\hline Daily biomass productivity $\left(\mathrm{g} \mathrm{L}^{-1}\right.$ day $\left.^{-1}\right)$ & $0.18 \pm 0.01^{\mathrm{a}}$ & $0.23 \pm 0.04^{\mathrm{a}}$ & $0.39 \pm 0.01^{\mathrm{b}}$ \\
\hline Specific growth rate, $0-3\left(\right.$ day $\left.^{-1}\right)$ & $0.33 \pm 0.06^{\mathrm{a}}$ & $0.67 \pm 0.06^{\mathrm{b}}$ & $0.77 \pm 0.03^{c}$ \\
\hline Biomass doubling time, 0-72 (h) & $51.3 \pm 9.44^{\mathrm{a}}$ & $24.9 \pm 2.22^{\mathrm{b}}$ & $21.5 \pm 0.95^{\mathrm{b}}$ \\
\hline \multicolumn{4}{|l|}{ Biochemical composition* } \\
\hline Protein content $(\%, w / w)$ & $24.13 \pm 5.02^{\mathrm{b}}$ & $35.36 \pm 7.05^{\mathrm{bc}}$ & $45.15 \pm 7.68^{c}$ \\
\hline Protein productivity $\left(\mathrm{mg} \mathrm{L}^{-1}\right)$ & $512.51 \pm 36.74^{\mathrm{a}}$ & $972.52 \pm 175.78^{\mathrm{b}}$ & $1902.14 \pm 335.16^{c}$ \\
\hline Daily protein productivity $\left(\mathrm{mg} \mathrm{L}^{-1}\right.$ day $\left.^{-1}\right)$ & $42.71 \pm 3.06^{\mathrm{a}}$ & $81.04 \pm 14.65^{\mathrm{b}}$ & $158.51 \pm 27.93^{c}$ \\
\hline Lipid content $(\%, w / w)$ & $14.13 \pm 5.02^{\mathrm{a}}$ & $13.74 \pm 2.09^{\mathrm{a}}$ & $13.48 \pm 2.95^{\mathrm{a}}$ \\
\hline Lipid productivity $\left(\mathrm{mg} \mathrm{L}^{-1}\right)$ & $299.48 \pm 21.47^{\mathrm{a}}$ & $376.80 \pm 68.11^{\mathrm{a}}$ & $568.75 \pm 100.22^{\mathrm{b}}$ \\
\hline Daily lipid productivity $\left(\mathrm{mg} \mathrm{L}^{-1}\right.$ day $\left.^{-1}\right)$ & $24.96 \pm 1.79^{\mathrm{a}}$ & $31.40 \pm 5.67^{\mathrm{a}}$ & $47.39 \pm 8.35^{\mathrm{b}}$ \\
\hline Carbohydrates content $(\%, w / w)$ & $61.82 \pm 0.98^{\mathrm{a}}$ & $32.62 \pm 3.54^{\mathrm{b}}$ & $24.97 \pm 3.20^{c}$ \\
\hline Carbohydrates productivity $\left(\mathrm{mg} \mathrm{L}^{-1}\right)$ & $1295.63 \pm 92.89^{\mathrm{a}}$ & $896.61 \pm 162.06^{\mathrm{b}}$ & $1053.23 \pm 185.58^{\mathrm{c}}$ \\
\hline Daily carbohydrates productivity $\left(\mathrm{mg} \mathrm{L}^{-1}\right.$ day $\left.^{-1}\right)$ & $107.97 \pm 77.74^{\mathrm{a}}$ & $87.77 \pm 15.46^{\mathrm{b}}$ & $74.71 \pm 13.50^{\mathrm{b}}$ \\
\hline \multicolumn{4}{|l|}{ Fatty acid profile* } \\
\hline Total C16-18 (\%,w/w) & $79.99 \pm 2.27^{\mathrm{a}}$ & $78.73 \pm 5.32^{\mathrm{a}}$ & $78.12 \pm 5.96^{\mathrm{a}}$ \\
\hline $\mathrm{SFA}^{\bullet}$ & $33.07 \pm 2.03^{\mathrm{a}}$ & $21.21 \pm 2.05^{\mathrm{b}}$ & $20.34 \pm 3.05^{\mathrm{b}}$ \\
\hline MUFA $\bullet$ & $35.76 \pm 2.03^{\mathrm{a}}$ & $26.76 \pm 1.93^{\mathrm{b}}$ & $23.22 \pm 2.80^{c}$ \\
\hline $\mathrm{PUFA}^{\bullet \bullet \bullet}$ & $11.16 \pm 3.58^{\mathrm{a}}$ & $30.77 \pm 4.10^{\mathrm{b}}$ & $34.56 \pm 5.29^{\mathrm{b}}$ \\
\hline$\omega 6: \omega 3$ ratio & $3.98 \pm 0.73^{\mathrm{a}}$ & $1.58 \pm 0.35^{\mathrm{b}}$ & $1.45 \pm 0.37^{\mathrm{b}}$ \\
\hline
\end{tabular}

Table 1. The influence of culture conditions on basis growth parameters, biochemical composition and fatty acid profile of Tetradesmus obliquus. *the results are presented as the means of 9 measurements from three biological replicates $\pm \mathrm{SD}$, means followed by the same letter are not significantly different; Tukey HSD test, $\alpha=0.05 .{ }^{\bullet}$-saturated fatty acids. ${ }^{\bullet}$ - monounsaturated fatty acids. ${ }^{\bullet \bullet}$ - polyunsaturated fatty acids.

The cellular biomass spectra of both species of green algae comprise two bands located between 1500-1700 $\mathrm{cm}^{-1}$ with a maximum at ca. $1640 \mathrm{~cm}^{-1}$ and $1540 \mathrm{~cm}^{-1}$, referred to amide I and amide II bands, respectively, and corresponding to symmetrical stretching vibrations of $\mathrm{C}=\mathrm{O}$ functional groups, symmetrical bending vibrations of $\mathrm{N}-\mathrm{H}$ groups, and symmetrical stretching vibrations of $\mathrm{C}-\mathrm{N}$ groups. The amide I and amide II bands are regions characteristic for proteins. Additionally, in the range of $1500-1700 \mathrm{~cm}^{-1}$, there are other bands corresponding to vibrations that can be assigned to protein functional groups with a maximum at ca. $1455 \mathrm{~cm}^{-1}$ and at $1380 \mathrm{~cm}^{-1}$, corresponding respectively to asymmetric bending vibrations of methyl and methylene groups and symmetrical bending vibrations of methyl and methylene groups and carboxylic groups. Additionally, there is a band in the range of $800-1800 \mathrm{~cm}^{-1}$ with a maximum at ca. $1735 \mathrm{~cm}^{-1}$, which is characteristic for symmetrical stretching vibrations of ester groups $(\mathrm{C}=\mathrm{O})$ in fats and fatty acids.

Figure $2 \mathrm{~b}$ presents FT-IR spectra of T. obliquus cellular biomass in the range of $2400-3600 \mathrm{~cm}^{-1}$ with a band corresponding to asymmetrical stretching vibrations of $\mathrm{C}-\mathrm{H}$ groups with a maximum at ca. $2920 \mathrm{~cm}^{-1}$. All spectra of the cellular biomass of the analysed green algae contain a broad band at $3000-3600 \mathrm{~cm}^{-1}$ with a maximum at ca. $3290 \mathrm{~cm}^{-1}$ typical for stretching vibrations of $\mathrm{O}-\mathrm{H}$ groups derived from water and stretching vibrations of N-H functional groups of proteins. Table 2 presents the detailed location of the maximum of absorption bands $\left(\mathrm{cm}^{-1}\right)$ characterizing lipid, carbohydrate, and protein regions in all the Tetradesmus obliquus culture variants.

The effect of the cultivation modes on the lipid and carbohydrate content in T. obliquus biomass can be observed from the ratio of the intensity of the lipid absorption bands with a maximum at $2920 \mathrm{~cm}^{-1}$ to the amide I band $\left(1640 \mathrm{~cm}^{-1}\right)$ for T. obliquus which were assigned as $\mathrm{L}_{\text {Tobliquus }} / \mathrm{AI}$. In turn, the ratio of the intensity of the absorption band of sugars with a maximum at $1020 \mathrm{~cm}^{-1}$ to the amide I band $\left(1640 \mathrm{~cm}^{-1}\right)$ for T. obliquus was assigned as $\mathrm{C}_{\text {T.obliquus }} / \mathrm{AI}$ (Fig. 3a,b). Based on the $\mathrm{L}_{\text {T.obliquus }} / \mathrm{AI}$ ratio with a value of 0.74 , the highest lipid content was found in T. obliquus cell biomass in the autotrophic culture. Based on the values of the ratio $\mathrm{L}_{\text {T.obliquus }} / \mathrm{AI}$ of 0.61 , the lowest lipid content was detected in T. obliquus from the photoheterotrophic culture. The T. obliquus biomass from the autotrophic culture was characterised by the highest carbohydrate content, which was indicated by the $\mathrm{C}_{\text {T.obliquus }} / \mathrm{AI}$ ratio of 1.86 .

Analysis of lipid, protein, and carbohydrate content. The biochemical composition has been determined with standard Bligh and Dyer ${ }^{18}$, Trevelyan ${ }^{19}$, and Kjeldah $l^{10}$ methods. The cell composition of T. obliquus, productivities, and daily productivities of individual cell components are shown in Table 1.

The results showed that there were no statistically significant differences in the lipid content in the T. obliquus cells. However, the highest lipid productivity $\left(568.7 \mathrm{mg} \mathrm{L}^{-1}\right)$ was obtained for the mixotrophic cultures. It was observed that the nutritional strategy had a significant effect on the protein content in the T. obliquus cells (Table 1$)$. The highest protein content $(45.15 \%)$ was obtained for the mixotrophic culture conditions, which resulted in high protein productivity. The mixotrophic conditions contributed to a significant decrease in the 

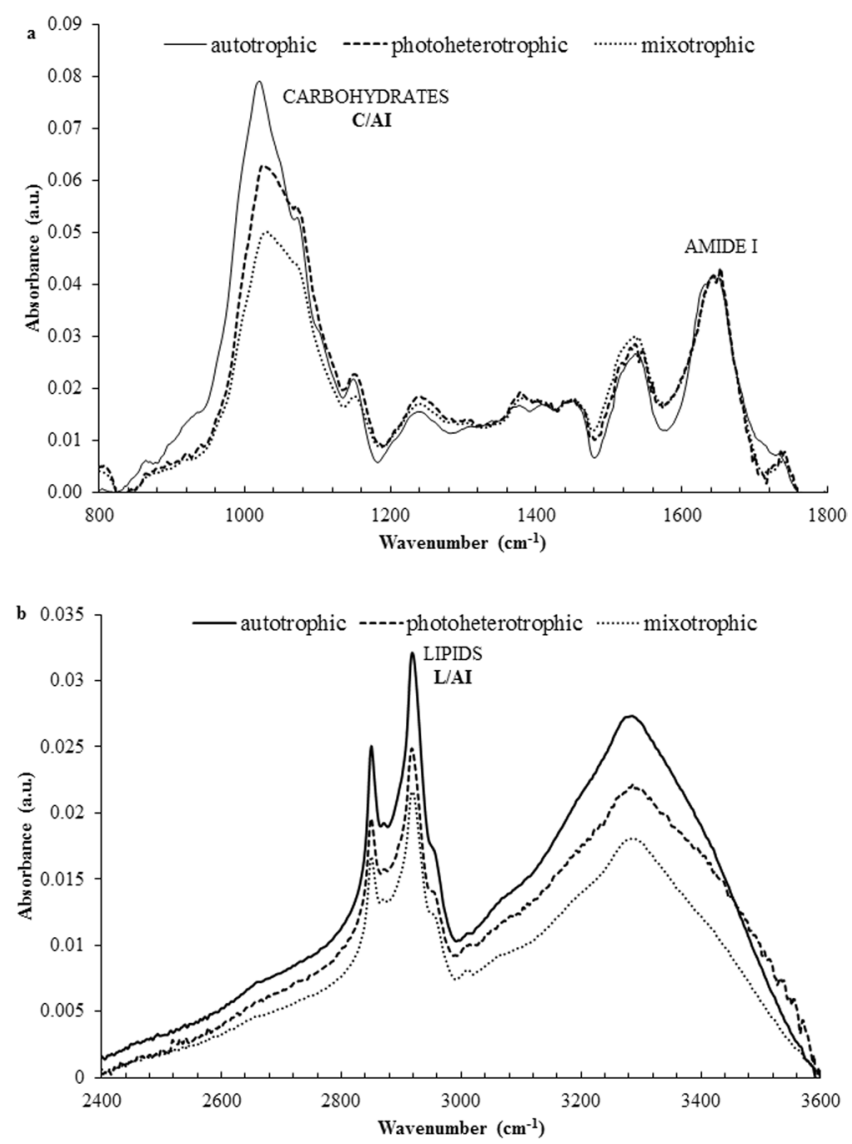

Figure 2. FT-IR spectra of Tetradesmus obliquus cell biomass growing under autotrophic, photoheterotrophic, and mixotrophic cultivation modes in the ranges from 800 to $1800 \mathrm{~cm}^{-1}$ (a) and from 2400 to $3600 \mathrm{~cm}^{-1}(\mathbf{b})$ (the results are presented as the mean spectra of at least 6 measurements from three biological replicates, the FT-IR spectra are normalized to amide I).

\begin{tabular}{|c|c|c|c|c|c|c|}
\hline \multirow{2}{*}{$\begin{array}{l}\text { Species } \\
\text { Tetradesmus } \\
\text { obliquus }\end{array}$} & \multicolumn{3}{|c|}{ Nutritional strategy } & \multirow[b]{2}{*}{$\begin{array}{l}\text { Type of binding and } \\
\text { functional group }\end{array}$} & \multirow[b]{2}{*}{ Macromolecule } & \multirow{2}{*}{$\begin{array}{l}\text { Wavenumber } \\
\text { range } \\
\left(\mathrm{cm}^{-1}\right)^{40,56,57}\end{array}$} \\
\hline & autotrophy & photoheterotrophy & mixotrophy & & & \\
\hline \multirow{13}{*}{ Wavelenghts $\left(\mathrm{cm}^{-1}\right)$} & 3286 & 3288 & 3288 & $\nu \mathrm{O}-\mathrm{H} / \nu \mathrm{N}-\mathrm{H}^{\bullet}$ & $\mathrm{H}_{2} \mathrm{O} /$ proteins & $3400-3200$ \\
\hline & 2954 & 2956 & 2956 & $\nu_{\mathrm{as}} \mathrm{CH}_{3}$ & \multirow{4}{*}{ lipids } & 2960 \\
\hline & 2917 & 2917 & 2917 & $v_{\mathrm{as}} \mathrm{CH}_{2}$ & & 2930 \\
\hline & 2850 & 2850 & 2850 & $\nu \mathrm{CH}_{2}, \nu \mathrm{CH}_{3}$ & & 2850 \\
\hline & 1731 & 1735 & 1739 & $\nu \mathrm{C}=\mathrm{O}$ & & 1740 \\
\hline & 1643 & 1643 & 1643 & $\nu \mathrm{C}=\mathrm{O}$ & \multirow{4}{*}{ proteins } & 1650 \\
\hline & 1536 & 1535 & 1536 & $\delta \mathrm{N}-\mathrm{H} / \nu \mathrm{C}-\mathrm{N}$ & & 1540 \\
\hline & 1454 & 1450 & 1454 & $\delta_{\mathrm{as}} \mathrm{CH}_{2}, \delta_{\mathrm{as}} \mathrm{CH}_{3}$ & & 1455 \\
\hline & 1376 & 1378 & 1382 & $\delta_{\mathrm{as}} \mathrm{CH}_{2}, \mathrm{CH}_{3} / \delta \mathrm{C}-\mathrm{O}$ & & 1390 \\
\hline & 1238 & 1238 & 1238 & $\nu_{\mathrm{as}} \mathrm{P}=\mathrm{O}$ & nukleic acids & 1240 \\
\hline & 1149 & 1151 & 1151 & $\nu \mathrm{C}-\mathrm{O}-\mathrm{C}$ & \multirow{3}{*}{ carbohydrates } & \multirow{3}{*}{$1200-900$} \\
\hline & 1072 & 1072 & 1072 & $\nu \mathrm{C}-\mathrm{O}-\mathrm{C} / \nu \mathrm{P}=\mathrm{O}$ & & \\
\hline & 1020 & 1025 & 1029 & $\nu \mathrm{C}-\mathrm{O}-\mathrm{C}$ & & \\
\hline
\end{tabular}

Table 2. Location of maxima of FTIR absorption bands for T. obliquus cell biomass. $\bullet=$ symmetric stretching, $\nu_{\mathrm{as}}=$ asymmetrical stretching, $\delta=$ symmetric deformation, $\delta_{\mathrm{as}}=$ asymmetrical deformation.

carbohydrate content, compared to the autotrophic mode. In all variants of the experiment, the high carbohydrate productivity ranged from $896.6 \mathrm{mg} \cdot \mathrm{L}^{-1}$ to $1259.6 \mathrm{mg} \cdot \mathrm{L}^{-1}$ for the photoheterotrophic and autotrophic conditions, respectively. The daily protein and lipid productivities (shown in Table 1) increased in the following order: autotrophic $<$ photoheterotrophic $<$ mixotrophic. In contrast, the daily carbohydrate productivity increased in the following series: mixotrophic $<$ photoheterotrophic $<$ autotrophic. 

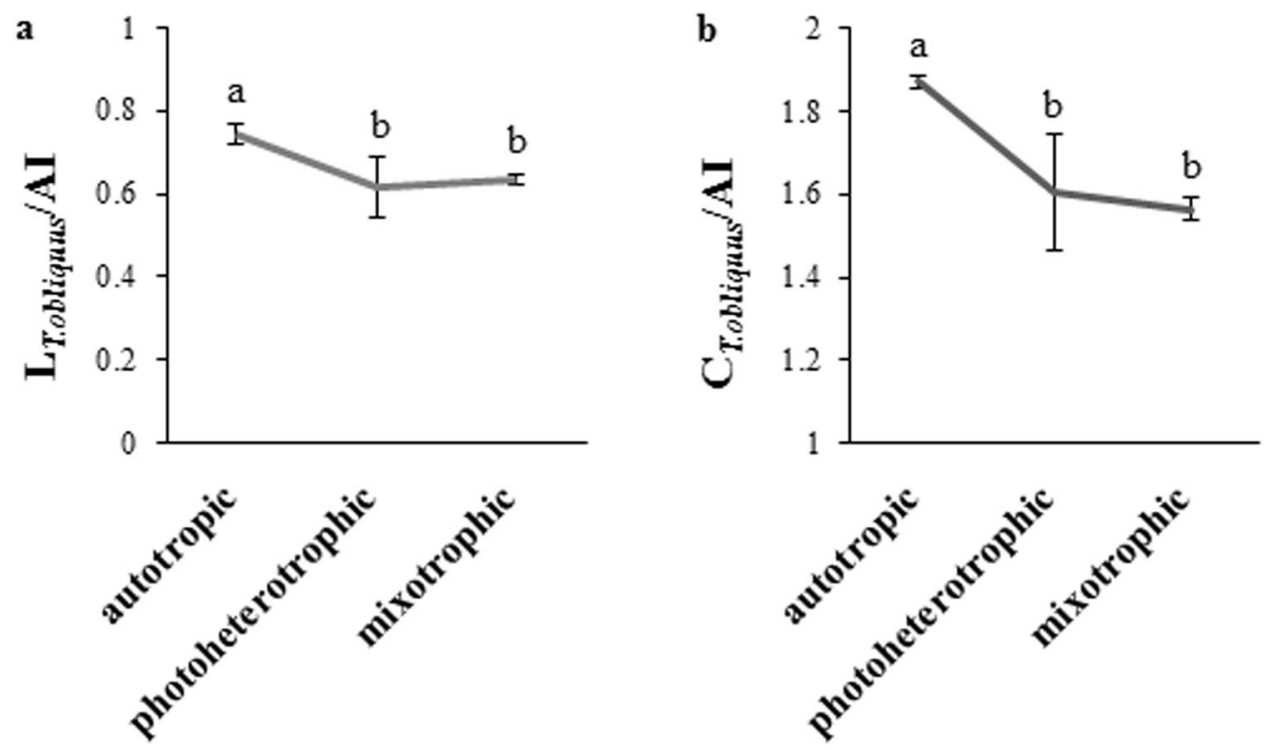

Figure 3. Comparison of the ratio of the intensity of the lipid absorption bands with a maximum at $2920 \mathrm{~cm}^{-1}$ $\left(\mathrm{L}_{\text {T.obliquus }}\right)$ to the amide I band at maximum at $1640 \mathrm{~cm}^{-1}(\mathrm{AI})$ assigned as $\left(\mathrm{L}_{\text {T.obliquus }} / \mathrm{AI}\right)(\mathbf{a})$ and the ratio of the intensity of the absorption band of carbohydrate with a maximum at $1020 \mathrm{~cm}^{-1}\left(\mathrm{C}_{\text {T.obliquus }}\right)$ to the amide I band at maximum at $1640 \mathrm{~cm}^{-1}(\mathrm{AI})$ assigned as $\left(\mathrm{C}_{\text {T.obliquus }} / \mathrm{AI}\right)(\mathbf{b})$ of T. obliquus at different nutritional strategies (the results are presented as the mean of at least 6 measurements from three biological replicates, error bars represent standard deviation, means followed by the same letter are not significantly different; Tukey HSD test, $\alpha=0.05)$.

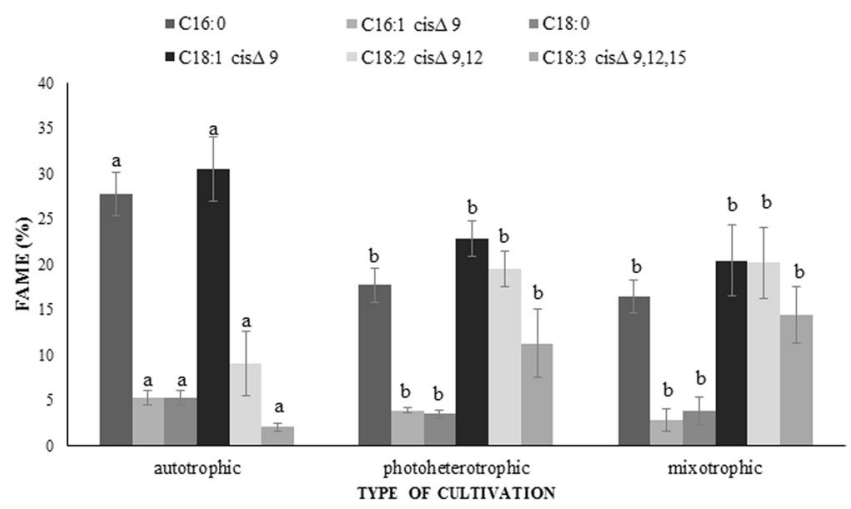

Figure 4. Influence of the nutritional strategies on the fatty acid profile in Tetradesmus obliquus cells (the results are presented as the mean of at least 6 measurements from three biological replicates, error bars represent SD, means followed by the same letter are not significantly different; Tukey HSD test, $\alpha=0.05$ ).

Analysis of fatty acid profile. Table 1 presents general characteristics of the fatty acid profile in T. obliquus cells as well as specification of the percentage of C16-C18 acids and the sum of saturated (SFA), monounsaturated (MUFA), and polyunsaturated (PUFA) fatty acids among the C16-C18 acids in all the culture variants.

In the control cultures, photoheterotrophic cultures, and mixotrophic cultures, C16-C18 fatty acids account for almost $80 \%$ of all fatty acids detected in T. obliquus cells. Depending on the culture conditions, the content of saturated, monounsaturated, and polyunsaturated fatty acids C16-C18 varies as well. The highest SFA and MUFA percentage was found in cells from the autotrophic culture. The differences between the SFA and MUFA percentages in all the culture variants were statistically significant. In the photoheterotrophic and mixotrophic cultures, there was a significant increase in the percentage of polyunsaturated fatty acids (PUFA) relative to the autotrophic culture.

Depending on the T. obliquus culture conditions, the abundance of individual fatty acids varied. The effect of the culture conditions on the percentage of C16-C18 fatty acids in the cellular biomass is presented in Fig. 4. The percentage of C16:0 and C16:1, cis $\Delta_{9}$ differs significantly between the culture variants. The highest percentage of C16:0 was detected in cells from the autotrophic culture (27.77\%). The photoheterotrophic culture and mixotrophic culture were characterised by a significant decrease in the percentage of C16:0, compared with the control culture. 
The T. obliquus cells exhibited the lowest percentage of C16:1, cis $\Delta_{9}$, i.e. $5.28 \%, 3.91 \%$, and $2.83 \%$ in the autotrophic, photoheterotrophic, and mixotrophic cultures, respectively. A significant decrease in the percentage of C16:1, cis $\Delta_{9}$ was noted in the photoheterotrophic and mixotrophic cultures, compared with the control. There were no statistically significant differences between the percentage of C16:0 and C16:1, cis $\Delta_{9}$ in cells from the photoheterotrophic and mixotrophic cultures.

The highest percentage of C18:0 was detected in T. obliquus cells from the control culture (5.30\%). There was also a significant decline in the percentage of C18:0 in cells from the other experimental cultures. The lowest C18:0 abundance, i.e. 3.52\% was detected in cells from the photoheterotrophic cultures. There were no significant differences in C18:0 percentage between cells from the photoheterotropic culture and the mixotrophic culture.

The highest percentage of C18:1, cis $\Delta_{9}(30.48 \%)$ was detected in T. obliquus cells growing in the autotrophic culture. In turn, a significant decrease in the percentage of C18:1, cis $\Delta_{9}$ was noted in the others experimental variants. In both cases, the molasses supplementation contributed to an increase in the content of polyunsaturated fatty acids. There were no significant differences in the percentage of C18:2, cis $\Delta_{9,12} \omega 6$, and C18:3, cis $\Delta_{9,12,15} \omega 3$ between cells from the photoheterotrophic and mixotrophic cultures. The highest amount of C18:2, cis $\Delta_{9,12} \omega 6$ (20.19\%) and C18:3, cis $\Delta_{9,12,15} \omega 3$ (14.37\%) was detected in the mixotrophic culture. Additionally, T. obliquus cells growing in the mixotrophic culture conditions were characterised by a significantly higher level of C18:2, cis $\Delta_{9,12}$ $\omega 6$ relative to that in the control. In turn, the ratio of the $\omega 6: \omega 3$ acids in Tetradesmus obliquus was 4:1, 1.6:1 and 1.5:1 in the autotrophic, photoheterotrophic, and mixotrophic cultures, respectively (Table 1).

\section{Discussion}

The short adaptation phase in the photoheterotrophic and mixotrophic culture conditions may result from the presence of organic carbon compounds derived from beet molasses in the culture medium. The short lag phase was caused by the rapid transport and diffusion of organic carbon in the form of reducing sugars into the cell using membrane transport protein $s^{20}$. The most assimilable hexoses, which are present in beet molasses, are rapidly and directly utilized by cells and converted into the central carbon metabolism, providing a large amount of energy in the form of ATP ${ }^{11,20,21}$. Zhang et al. ${ }^{22}$ also observed that, especially at a low concentration in culture medium, glucose shortened the lag phase, as it was assimilated easily during the cultivation.

In comparison to the autotrophic mode, an increase the final biomass concentration and specific growth rate was observed in the photoheterotrophic and mixotrophic culture conditions. In the present studies, the mixotrophic T. obliquus culture conditions were characterized by the highest biomass yield and specific growth rate as well as the shortest biomass doubling time. As reported by Yang et al. ${ }^{23}$, simultaneous supply of light, $\mathrm{CO}_{2}$, and an organic carbon source to the medium induced the mixotrophic growth of algae and resulted in the highest final biomass yield. It can be assumed that the highest biomass yield was the result of simultaneous photosynthetic carbon and organic carbon uptake. Organic carbon is supplied to algal cells through active transport and phosphorylation ${ }^{24}$. Kamalanathan et al. ${ }^{25}$ reported that the photosynthetic activity of Scenedesmus obliquus during molasses-based mixotrophic growth was comparable with that of cells in photoautotrophic cultures. The researchers showed that Scenedesmus obliquus cultured in mixotrophic conditions had a fully functional photosynthetic apparatus.

In T. obliquus cells cultured in autotrophic conditions, the highest carbohydrate content was detected using both spectrophotometric analysis and infrared spectroscopy. Cells cultivated in autotrophic growth conditions are mainly a source of carbohydrates ${ }^{26}$. Thus, the presence of a sufficient amount of $\mathrm{CO}_{2}$ significantly influences the carbohydrate accumulation in microalgae. Additionally, the increasing $\mathrm{CO}_{2}$ concentration has an impact on carbohydrate accumulation ${ }^{12,27}$.

The Tetradesmus obliquus cells had high-protein content in the photoheterotrophic and especially in the mixotrophic growth conditions. This result confirms the fact that both the nitrogen and carbon sources present in the medium target the metabolism towards protein synthesis and intensification of cell growth ${ }^{28}$. Beet molasses is mainly a source of organic compounds in the form of sucrose and reducing sugars. Besides organic carbon, molasses contains nitrogen in the form of nitrates, nitrites, and amino acids (Table 3 ). Additional nitrogen originating from the source is directly involved in the synthesis and accumulation of cellular proteins ${ }^{10}$. Protein is the main component constituting up to $60 \%$ of marine and freshwater algal cells and cyanobacterial cultures growing in nitrogen conditions ${ }^{29}$. Nitrogen is responsible for stimulation of the growth of algae and ensures the synthesis of proteins involved in carbon assimilation ${ }^{30}$. At $\mathrm{N}$-repletion in the culture medium, Chlamydomonas reinhardtii cells were characterized by an increase in transcripts for genes encoding photosynthetic complexes, electron transport chain, photosynthetic antenna systems, pigments synthesis, and Calvin-Benson cycle ${ }^{31}$. N-repletion promotes RuBisCO synthesis, which is the largest reservoir of nitrogen in cells in stress conditions ${ }^{32,33}$. In nitrogen availability conditions, algal cells were also characterized by high content of free intracellular nitrogen compounds, i.e. free nitrates and free amino acids ${ }^{34}$. The control of metabolism and targeting the metabolic pathways towards synthesis and accumulation thereof can be an opportunity for development of many branches of industry, e.g. pharmacy, medicine, and cosmetics.

The presence of an organic form of carbon in the culture medium, most often glucose ${ }^{9}$, has an impact on the lipid content in algal cells. Additionally, nitrogen deficiency in the environment causes redirection of the metabolism towards the synthesis of reserve material in the cell in the form of triacylglycerols or starch ${ }^{35}$. Generally, lipid synthesis in cells occurs upon depletion of nitrogen in the environment ${ }^{36,37}$, at a high carbon/nitrogen ratio in the culture medium $(\mathrm{C} / \mathrm{N})^{38}$. The results obtained by modified Bligh \& Dyer method indicate that T. obliquus cells have similar lipid content in all culture variants. In contrast, the qualitative FTIR analysis of the cells showed reduced lipid content in T. obliquus cells from the photoheterotrophic and mixotrophic cultures, compared to the autotrophic cultures. The differences in the results of the cell lipid content are a consequence of the method used for the analysis. The Bligh \& Dyer extraction method is used for all extractable compounds in solvents, including chlorophyll ${ }^{39}$, and the FTIR determination of the lipid content was based on the stretching vibration 
band of the methylene group $\left(\mathrm{CH}_{2}\right)$ characteristic for lipids ${ }^{40}$. This study indicates that the photoheterotrophic and mixotrophic culture of T. obliquus provided the cells with optimal environmental conditions and all necessary biogenic elements, mainly carbon and nitrogen without inducing stress, which results in reduced lipid content. The lipid content in the T. obliquus cells are close to the average lipid content in algal cells growing in optimal environmental conditions, i.e. $25.5 \%$ suggested by Hu et al ${ }^{41}$ and $23 \%$ (green algae) proposed by Griffiths \& Harrison ${ }^{42}$. Accumulation of lipids is a protective mechanism in algal cells induced by exposure to stress. In optimal environmental conditions, algal cells mainly contain polar membrane lipids ${ }^{35}$. The present results agree with those reported by Yan et al. ${ }^{36}$, who demonstrated that the presence of nitrogen in molasses did not affect lipid accumulation in Chlorella protothecoides cells in heterotrophic growth conditions, and lipid accumulation was observed only in the case of a glucose-enriched medium with reduced nitrogen content.

Regardless of the culture conditions, the fatty acid profile in T. obliquus is dominated by acids containing from 16 to 18 carbon atoms in the carbon chain. This is typical for Chlorophyta, which is confirmed in the literature ${ }^{43}$. In the photoheterotrophic and mixotrophic modes, the percentage of individual fatty acids and the content of SFA, MUFA, and PUFA groups were different from those in the autotrophic culture conditions. Literature data on the fatty acid profile in Chlorophyta under beet molasses supplementation are very scarce. Only two studies describe the effect of molasses of unknown origin on the fatty acid profile in Chlorella protothecoides ${ }^{36}$ and Chlorella minutissima ${ }^{44}$. Yan et al. ${ }^{36}$ observed that molasses addition to culture medium caused an increase in the linoleic acid content. The fatty acid content is variable; every species described in the literature functions differently in different environmental conditions. The fatty acid composition in T. obliquus was affected by additional nitrogen in the culture medium. Nitrogen deficiency in the culture medium can decrease the content of linolenic acid in algal cells. This is directly linked to the activity of the gene encoding the - $\Delta 15$ desaturase enzyme involved in formation of linolenic acid ${ }^{45}$. The activity of enzymes involved in the synthesis and transformation of fatty acids depends on the presence of nitrogen in the culture medium. T. obliquus cells growing under $\mathrm{N}$ supply are characterized by high content of linolenic acid, suggesting increased $\Delta 15$ desaturase activity. T. obliquus cells growing in the presence of beet molasses (both photoheterotrophic and mixotrophic culture conditions) produced high amounts of oleic acid, linoleic acid C18: 2, $\operatorname{cis}_{\Delta 9,12, \omega 6}$ (LA) and $\alpha$-linolenic acid 18: 3, $\operatorname{cis}_{\Delta 9,12,15}, \omega 3$ (ALA). Linoleic acid and $\alpha$-linolenic acid are essential fatty acids (EFA). LA is a precursor for the synthesis of $\omega 6$ long chain acids, including arachidonic acid (ARA) and ALA is converted to long chain $\omega 3$ acids such as eicosapentaenoic acid (EPA) and docosahexaenoic acid (DHA) ${ }^{14}$. Essential fatty acids from both the $\omega 3$ and $\omega 6$ families are indispensable for the proper function of the human organism and must be provided through dietary intake, as they cannot be synthesized in the human body ${ }^{14-16}$. The major dietary sources of LA are vegetable oils sunflower, corn, safflower, peanut, and olive oil, whereas ALA it is found, in vegetable oils, seeds, nuts, legumes, grains, fruits, and some wild plants, in addition to algae. ALA is the most important $\omega 3$ fatty acid in the human diet. It takes part in reduction of the risk of degenerative diseases e.g. heart and cancer diseases, arthritis, skin conditions, diabetic neuropathy, immune function, and premenstrual syndrome ${ }^{46}$.

Omega 6 acids are supplied to the human organism in substantial amounts, whereas the amount of $\omega 3$ acids is very low. This leads to a disturbed ratio of $\omega 6: \omega 3$ fatty acids. Inappropriate proportions may contribute to the development of many serious diseases. The World Health Organization (WHO) recommends consuming products in a diet with a $\omega 6: \omega 3$ acid ratio lower than 10:177,48. The optimal ratios fluctuate between $4: 1$ and $1: 1^{49}$. Tetradesmus obliquus is characterized by having ratios of $4: 1,1.6: 1$ and $1.5: 1$ of $\omega 6: 3$ in the autotrophic, photoheterotrophic, and mixotrophic cultures, respectively. Therefore, T. obliquus cells derived from molasses-supplemented cultures seem to be suitable for dietary supplementation of essential fatty acids.

With algal capability of simultaneous biosynthesis of several metabolites, algal cell biomass is used in many fields of biotechnology. Algal species exhibit this ablilty include e.g. Phaeodactylum tricornutum, which are able to synthesize lipids and fucoxanthins simultaneously ${ }^{50}$ and Odontella aurita, which synthesize EPA acid and fucoxanthin $^{51}$. Due to the high protein content and productivity as well as the presence of essentials fatty acids with a favourable $\omega 6: \omega 3$ ratio, Tetradesmus obliquus cells growing on a beet molasses-supplemented medium, are important for biotechnological applications and can be used in human and animal nutrition and supplementation.

\section{Materials and Methods}

Characterization of the species and algal culture conditions. The green algae Tetradesmus obliquus (strain No. 276-1) were obtained from the Culture Collection of Algae (SAG) at Göettingen University. The inoculation culture of T. obliquus was carried out in Erlenmeyer flasks containing $50 \mathrm{~cm}^{3}$ and successive $250 \mathrm{~cm}^{3}$ of liquid mineral Bold's Basal Medium (BBM). During the pre-cultivation ambient temperature $\left(25^{\circ} \mathrm{C}\right)$, light intensity $\left(80 \mu \mathrm{mol}\right.$ photons $\left.\mathrm{m}^{-2} \mathrm{~s}^{-1}\right)$, photosynthetic radiation (fluorescence lamps - Philips Aquarelle) and continuous light ( $24 \mathrm{~h}$ light $/ 0 \mathrm{~h}$ dark) were monitored. The T. obliquus cells were cultured on a laboratory shaker to prevent sedimentation.

Batch cultures of T. obliquus were established in BIOSTAT PBR 2 S Sartorius Stedim Biotech photobioreactors by application of the inoculum obtained in the preliminary culture. The initial optical density $\left(\mathrm{OD}_{650}\right)$ was 0.5 . The T. obliquus cells were cultured in autotrophic, photoheterotrophic, and mixotrophic growth conditions, which corresponded to the aerated culture (control), molasses-supplemented culture, and aerated molasses-supplemented culture. Each culture variant was performed in three independent biological replicates. Filtered sterile atmospheric air at a flow of $12 \mathrm{~L} \mathrm{~h}^{-1}$ was constantly supplied to the aerated cultures (autotrophic and mixotrophic cultivation modes). Molasses at a concentration of $10 \mathrm{~g} \mathrm{~L}^{-1}$ was used as a substrate for enrichment of the photoheterotrophic and mixotrophic cultures. The beet molasses was provided by a local sugar factory. Its composition is presented in the Table 3 . The batch cultures were carried out at a temperature of $25 \pm 1{ }^{\circ} \mathrm{C}$ under continuous light with light intensity of $80 \mu \mathrm{mol}$ photons $\mathrm{m}^{-2} \mathrm{~s}^{-1}$ for 12 days. The biomass was harvested by centrifuging after 12 and used for further biochemical analyses. 


\begin{tabular}{|l|l|}
\hline Parameters & Value \\
\hline Apparent dry matter, ${ }^{\circ} \mathrm{Bx}$ & 80.1 \\
\hline Apparent sucrose, $\%$ & 49.4 \\
\hline $\mathrm{pH}$ & 8.6 \\
\hline Reducing sugars, \% & 0.16 \\
\hline Total nitrogen, $\%$ & 1.98 \\
\hline $\mathrm{SO}_{2}, \%$ & 0.009 \\
\hline $\mathrm{Ca}$ and $\mathrm{Mg}(\mathrm{salts}), \%$ & 0.14 \\
\hline Volatile acids, $\%$ & 0.94 \\
\hline Total organic carbon, $\%$ & 34.6 \\
\hline Total nitrite, $\mathrm{mg} / \mathrm{kg}$ & $<0.667$ \\
\hline Total nitrate, $\mathrm{mg} / \mathrm{kg}$ & 2600 \\
\hline Glutamic acid, g/kg & 29.6 \\
\hline Aspartic acid, g/kg & 3.02 \\
\hline
\end{tabular}

Table 3. Characteristics of beet molasses.

Measurement of cell biomass concentration and determination of growth curves. During the cultivation in the photobioreactors, spectrophotometric measurements of optical density $\left(\mathrm{OD}_{650}\right)$ were carried out every $24 \mathrm{~h}$ using a Cary 300/Biomelt spectrophotometer. Based on the calibration curve equation for $T$. obliquus $\left(\mathrm{DCW}=303.21 \times \mathrm{OD}_{650}-2.354, R^{2}=0.9958\right)$ and the determined optical density values, the theoretical dry cell weight (expressed in $\mathrm{g} \mathrm{L}^{-1}$ ) was determined during the consecutive days of cultivation, demonstrating the growth of the cultured T. obliquus cells ${ }^{52}$.

Determination of the basic growth parameters. The basic parameters for evaluation of unicellular algal growth, i.e. biomass yield (the final biomass concentration), the specific growth rate, and the biomass doubling time, were used to assess the cell growth in the culture. These parameters are used to describe the kinetics of unicellular algal growth in batch cultures.

The specific growth rate $(\mu)$ is a measure of the rate of algal growth in the logarithmic phase. It was calculated using Eq. 1 for the first three days of cultivation.

$$
\mu\left(\text { day }^{-1}\right)=\ln \left(\mathrm{N}_{2} / \mathrm{N}_{1}\right) /\left(\mathrm{T}_{2}-\mathrm{T}_{1}\right)
$$

where: $\mathrm{N}_{1}$ and $\mathrm{N}_{2}$ are the optical density values at $\mathrm{OD}_{650}$ and time $\mathrm{T}_{2}$ and $\mathrm{T}_{1}$, respectively.

The biomass doubling time $\left(T_{d}\right)$ was calculated based on the specific growth rate using Eq. 2 during the first 72 hours of cultivation. The biomass doubling time was expressed in hours.

$$
T_{d}=(\ln 2 / \mu) \times 24
$$

where: $\mu$ is specific growth rate.

The biomass yield after the cultivation was expressed in $\mathrm{g} \mathrm{L}^{-1}$. In turn, the daily biomass productivity was expressed in $\mathrm{g} \mathrm{L}^{-1}$ day $^{-110,53,54}$.

Analysis of biochemical composition - lipids, proteins, and carbohydrates. Lipid content was determined in the algal biomass with the gravimetric method, which is a modification of the Bligh and Dyer method $^{18,52}$. An ultrasound-assisted lipid extraction method with the use of a chloroform and methanol mixture in a volume ratio of $1: 2 \mathrm{v} / \mathrm{v}$ was employed. After the extraction, the solvent was evaporated on a Heidolph vacuum evaporator at a temperature of $40^{\circ} \mathrm{C}$. The lipid content was determined gravimetrically and expressed in $\%$ $(\mathrm{m} / \mathrm{m})$; next, the extract was suspended in 99\% $\mathrm{n}$-hexane (HPLC grade, Sigma-Aldrich). The samples were stored in a freezer until further determinations.

The total content of simple sugars was determined colorimetrically with the anthrone method ${ }^{19}$. A $2 \%$ anthrone solution in $98 \% \mathrm{H}_{2} \mathrm{SO}_{4}$ was added to the cell suspension. The samples were heated in a boiling-water bath for $10 \mathrm{~min}$. After cooling to room temperature, the absorbance of the samples at $620 \mathrm{~nm}$ was measured spectrophotometrically with using Cary 300/Biomelt. The content of soluble simple sugars $\left(\mathrm{mg} \mathrm{ml}^{-1}\right)$ was determined using the calibration curve prepared for the glucose standard. The carbohydrate content was expressed in $\%(\mathrm{~m} / \mathrm{m})$.

The Kjeldahl method was used to determine the total nitrogen and protein content in the algal cells ${ }^{10}$. To calculate the total protein content, the total nitrogen content was multiplied by an algae-specific nitrogen-to-protein conversion factor of $5.95^{55}$ in accordance with Eq. 3.

$$
\text { Total protein[\% d. w.] }=\mathrm{N} \times 5.95
$$

where: $\mathrm{N}$ - total nitrogen content [\% d.w.].

Protein, lipid, and carbohydrate productivities $\left(\mathrm{mg} \mathrm{L}^{-1}\right)$, the daily protein, lipid, and carbohydrate productivities $\left(\mathrm{mg} \mathrm{L}^{-1}\right.$ day $\left.^{-1}\right)$ were calculated based on the percentage content of cellular components and the biomass yield $\left(\mathrm{g} \mathrm{L}^{-1}\right)$. 
Determination of fatty acid methyl ester content. The mixture of fatty acid methyl esters was obtained by transesterification of lipids with methanol in the presence of catalysts ${ }^{13}$. Briefly, crude oil suspended in n-hexane (HPLC grade, Sigma-Aldrich) was evaporated and 0.5 M KOH-methanol (Sigma-Aldrich) was added and hydrolyzed at the temperature of $80^{\circ} \mathrm{C}$. Esterification was carried out by adding $10 \% \mathrm{BF}_{3}$ in methanol (for GC derivatization, Fluka). The reaction was performed at $100^{\circ} \mathrm{C}$ for $20 \mathrm{~min}$. Next, $99 \% \mathrm{n}$-hexane (HPLC grade, Sigma-Aldrich) and a saturated $\mathrm{NaCl}$ solution (Sigma-Aldrich, Supelco) were successively added. Separation of methyl esters and determination of fatty acids was performed on a Trace GC Ultra gas chromatograph coupled with ion trap mass spectrometer ITQ 1100 (GC/MS) from Thermo Scientific using a Rtx-2330 column, with a length of $105 \mathrm{~m}$, inner diameter of $0.25 \mathrm{~mm}$, and film thickness of $0.25 \mu \mathrm{m}$. Helium at a flow rate of $2.4 \mathrm{ml} / \mathrm{min}$ was the carrier gas. To determine the fatty acid composition, separation of the mixture of standard solutions -37 Component FAME Mix solutions (Sigma-Aldrich, Supelco) was carried out.

Qualitative analysis of algal biomass with the use of FT-IR spectroscopy. The infrared spectrometric analyses were carried out using an FT-IR spectrometer (Fourier Transform Infrared) - Nicolet 6700 (Thermo Electron Corporation, USA) with a single-reflective ATR (Attenuated Total Reflection) diamond-attachment. The spectrometer facilitates measurement in the infrared range from 4000 to $600 \mathrm{~cm}^{-1}$ with a resolution of $4 \mathrm{~cm}^{-1}$. The number of scans was 128 . The measurements demonstrated three spectra for each culture, which was an independent biological replication. In total, 9 spectra were obtained for each cultivation variant. The spectra were normalized to the amide I band at $1640 \mathrm{~cm}^{-1}$, which is the most intense band and, on their basis, the mean representative FT-IR spectrum was determined for each variant of the culture ${ }^{40}$. The content of carbohydrates and lipids in the biomass was assessed by determination of the intensity of the sugar band $\left(1025 \mathrm{~cm}^{-1}\right)$ to the protein band (amide I band $-1640 \mathrm{~cm}^{-1}$ ) and the ratio of the intensity of the lipid band $\left(2917 \mathrm{~cm}^{-1}\right)$ to the protein band (amide I band $-1640 \mathrm{~cm}^{-1}$ ).

Statistical analysis of results. Statistical analysis of the investigation results was carried out in the STATISTICA 12 program (StatSoft Inc., USA). To determine the impact of the nutrition strategy on the analysed quantitative and qualitative parameters of algal biomass, two-factor analysis of variance was carried out, and the significance of the differences was tested at a significance level of $p \leq 0.05$ using the post-hoc Tukey test.

Received: 15 January 2020; Accepted: 20 March 2020;

Published online: 14 April 2020

\section{References}

1. Mahapatra, D. M, Varma, V. S., Muthusamy, S. \& Rajendran, K. Wastewater Algae to Value-Added Products in Waste to Wealth. Energy, Environment, and Sustainability (eds. Singhania, R., Agarwal, R., Kumar, R., Sukumaran, R.) (Springer, 2018).

2. Magierek, E. \& Krzemińska, I. Effect of stress conditions on improvement of lipid and carbohydrate accumulation under photoautotrophic cultivation of Chlorophyta. Phycologia 57, 601-618 (2018).

3. Wang, L. et al. Anaerobic digested dairy manure as a nutrient supplement for cultivation of oil-rich green microalgae Chlorella sp. Bioresource Technol. 101, 2623-2628 (2010).

4. Wang, H., Xiong, H., Hui, Z. \& Zeng, X. Mixotrophic cultivation of Chlorella pyrenoidosa with diluted primary piggery wastewater to produce lipids. Bioresource Technol. 104, 215-220 (2012)

5. Rattanapoltee, P. \& Kaewkannetra, P. Utilization of Agricultural Residues of Pineapple Peels and Sugarcane Bagasse as Cost-Saving Raw Materials in Scenedesmus acutus for Lipid Accumulation and Biodiesel Production. Appl Biochem Biotech. 173, 1495-1510 (2014).

6. Lu, Y., Zhai, Y., Liu, M. \& Wu, Q. Biodiesel production from algal oil using cassava (Manihot esculenta Crantz) as feedstock. J Appl Phycol. 22, 573-578 (2010).

7. Gao, C., Zhai, Y., Ding, Y. \& Wu, Q. Application of sweet sorghum for biodiesel production by heterotrophic microalga Chlorella protothecoides. Appl Energ. 87, 756-761 (2010)

8. Cheng, Y. et al. Biodiesel production from Jerusalem artichoke (Helianthus Tuberosus L.) tuber by heterotrophic microalgae Chlorella protothecoides. J Chem Technol Biot. 84, 777-781 (2009).

9. Krzemińska, I. \& Oleszek, M. Glucose supplementation-induced changes in the Auxenochlorella protothecoides fatty acid composition suitable for biodiesel production. Bioresource Technol. 218, 1294-1297 (2016).

10. Piasecka, A., Krzemińska, I. \& Tys, J. Enrichment of Parachlorella kessleri biomass with bioproducts: oil and protein by utilization of beet molasses. J Appl Phycol. 29, 1735-1743 (2017).

11. Zhan, J., Rong, J. \& Wang, Q. Mixotrophic cultivation, a preferable microalgae cultivation mode for biomass/bioenergy production, and bioremediation, advances and prospect. Int J Hydrogen Energ. 42, 8505-8517 (2017).

12. Ji, M.-K. et al. Mixotrophic cultivation of a microalga Scenedesms obliquus in municipal wastewater supplemented with food wastewater and flue gas $\mathrm{CO}_{2}$ for biomass production. J Environ Manag. 159, 115-120 (2015).

13. Krzemińska, I., Piasecka, A., Nosalewicz, A., Simionato, D. \& Wawrzykowski, J. Alterations of the lipid content and fatty acid profile of Chlorella protothecoides under different light intensities. Bioresource Technol. 196, 72-77 (2015).

14. Wells, M. L. et al. Algae as nutritional and functional food sources: revisiting our understanding. J Appl Phycol. 29, 949-982 (2017).

15. Murff, H. J. \& Edwards, T. L. Endogenous Production of Long-Chain Polyunsaturated Fatty Acids and Metabolic Disease Risk. Curr Cardiovasc Risk Rep. 8, 418 (2014)

16. Guo, F., Kainz, M. J., Sheldon, F. \& Bunn, E. S. The importance of high-quality algal food sources in streamfood webs-current status and future perspectives. Freshw Biol. 61, 815-831 (2016).

17. Girard, J. et al. Mixotrophic cultivation of green microalgae Scenedesmus obliquus on cheese whey permeate for biodiesel production. Algal Res. 5, 241-248 (2014).

18. Bligh, E. G. \& Dyer, W. J. A rapid method for total lipid extraction and purification. Can J Biochem Physiol. 37, 911-917 (1959).

19. Trevelyan, W. E., Forrest, R. S. \& Harrison, J. S. Determination of yeast carbohydrates with the anthrone reagent. Nature. 170, 626-627 (1952).

20. Gao, C. et al. Oil accumulation mechanisms of the oleaginous microalga Chlorella protothecoides revealed through its genome, transcriptomes and proteomes. BMC Genomics. 15, 582 (2014).

21. Khan, M., Karmakar, R., Banani, D., Diba, F. \& Razu, M.H. Heterotrophic growth of microalgae in. Recent Advances in Microalgal Biotechnology (eds. Liu, J., Sun, Z. \& Gerken, H.) (Omnics Group eBooks, 2016).

22. Zhang, H., Wang, W., Li, Y., Yang, W. \& Shen, G. Mixotrophic cultivation of Botryococcus braunii. Biomass Bioenerg. 35, 1710-1715 (2011). 
23. Yang, C., Hua, Q. \& Shimizu, K. Energetics and carbon metabolism during growth of microalgal cells under photoautotrophic, mixotrophic and cyclic light-autotrophic/dark-heterotrophic conditions. Biochem Eng J. 6, 87-102 (2000).

24. Markou, G., Vandamme, D. \& Muylaert, K. Microalgal and cyanobacterial cultivation: The supply of nutrients. Water Res. 85, 186-202 (2014)

25. Kamalanathan, M., Dao, L. H. T., Chaisutyakorna, P., Gleadow, R. \& Beardall, J. Photosynthetic physiology of Scenedesmus sp. (Chlorophyceae) under photoautotrophic and molasses-based heterotrophic and mixotrophic conditions. Phycologia 56, 666-674 (2017).

26. Boyle, N. R. \& Morgan, J. A. Flux balance analysis of primary metabolism in Chlamydomonas reinhardtii. BMC Syst Biol. 7, 4 (2009).

27. Xia, J. R. \& Gao, K. S. Impacts of elevated $\mathrm{CO}_{2}$ concentration on biochemical composition, carbonic anhydrase and nitrate reductase activity of freshwater green algae. J Integr Plant Biol. 47, 668-675 (2005).

28. Fan, J. et al. Oil accumulation is controlled by carbon precursor supply for fatty acid synthesis in Chlamydomonas reinhardtii. Plant Cell Physiol. 53, 1380-1390 (2012).

29. Geider, R. J. \& La Roche, J. Redfield revisited: variability of C:N:P in marine microalgae and its biochemical basis. Eur J Phycol. 37, $1-17(2002)$.

30. Pego, J. V., Kortstee, A. J., Huijser, C. \& Smeekens, S. C. M. Photosynthesis, sugars and the regulation of gene expression. J Exp Bot. 51, 407-416 (2000).

31. Juergens, M. T. et al. The regulation of photosynthetic structure and function during nitrogen deprivation in Chlamydomonas reinhardtii. Plant Physiol. 167, 558-73 (2015).

32. Losh, J. L., Young, J. N. \& Morel, F. M. M. Rubisco is a small fraction of total protein in marine phytoplankton. New Phytol. 198, $52-58(2013)$.

33. Schmollinger, S. et al. Nitrogen-Sparing Mechanisms in Chlamydomonas Affect the Transcriptome, the Proteome, and Photosynthetic Metabolism. Plant Cell. 26, 1410-1435 (2014).

34. Hockin, N. L., Mock, T., Mulholand, F., Kopriva, S. \& Malin, G. The Response of Diatom Central Carbon Metabolism to Nitrogen Starvation Is Different from That of Green Algae and Higher Plants. Plant Physiol. 158, 299-312 (2012).

35. Procházková, G., Brányiková, I., Zachleder, V. \& Brányik, T. Effect of nutrient supply status on biomass composition of eukaryotic green microalgae. J Appl Phycol. 26, 1359-1377 (2014).

36. Yan, D., Lu, Y., Chen, Y. F. \& Qingyu, W. Waste molasses alone displaces glucose-based medium for microalgal fermentation towards cost-saving biodiesel production. Bioresource Technol. 102, 6487-6493 (2011).

37. Levering, J., Broddrick, J. \& Zengler, K. Engineering of oleaginous organisms for lipid production. Curr Opin Biotech. 36, 32-39 (2015).

38. Liu, J. et al. Utilization of cane molasess towards cost-saving astaxantin production by a Chlorella zofingiensis mutant. J Appl Phycol. 25, 1447-1456 (2013)

39. Su, C. H. et al. Simultaneous estimation of chlorophyll a and lipid contents in microalgae by three-color analysis. Biotechnol Bioeng. 99, 1034-1039 (2008)

40. Krzemińska, I., Nawrocka, A., Piasecka, A., Jagielski, P. \& Tys, J. Cultivation of Chlorella protothecoides in photobioreactors: The combined impact of photoperiod and $\mathrm{CO}_{2}$ concentration. Eng Life Sci. 15, 533-541 (2015).

41. Hu, Q. et al. Microalgal triacylglycerols as feedstocks for biofuel production: perspectives and advances. Plant J 54, 621-639 (2008).

42. Griffiths, M. J. \& Harrison, S. T. L. Lipid productivity as a key for choosing algal species for biodiesel production. J Appl Phycol 21, 493-507 (2009).

43. Borowitzka, M.A., Beardall, J. \& Raven, J.A. The Physiology of Microalgae (Springer International Publishing, 2016).

44. Gautam, K., Pareek, A. \& Sharma, D. K. Biochemical composition of green alga Chlorella minutissima in mixotrophic cultures under the effect of different carbon sources. J Biosci Bioeng. 116, 624-627 (2013).

45. Cha, T. S., Chen, J. W., Goh, E. G., Aziz, A. \& Loh, S. H. Differential regulation of fatty acid biosynthesis in two Chlorella species in response to nitrate treatments and the potential of binary blending microalgae oils for biodiesel application. Biores Technol. 102, 10633-10640 (2011).

46. Nigam, D., Yadav, R. \& Tiwari, U. Omega-3 Fatty Acids and Its Role in Human Health in Functional Food and Human Health (eds. Rani, V. \& Yadav, U) 173-180 (Springer, 2018).

47. Martins, D. A. et al. Alternative Sources of n-3 Long-Chain Polyunsaturated Fatty Acids in Marine Microalgae. Mar Drugs. 11, 2259-2281 (2013).

48. Shanab, S. M. M., Hafez, R. M. \& Fouad, A. S. A review on algae and plants as potential source of arachidonic acid. J Adv Res. 11, 3-13 (2018).

49. Rubio, V.P., Paniagua-Michel, J., \& Olmos, J. Omegas: Pharmaceutical High Value Products and One of the Most Functional Bioactive Compounds in Marine Algae Extracts: Processes, Products, Applications (eds. Kim, S.K. \& Chojnacka, K.) 229-232 (WILEY-VCH Verlag GmbH \& Co. KGaA, 2015).

50. Kim, S. M. et al. A Potential Commercial Source of Fucoxanthin Extracted from the Microalga Phaeodactylum tricornutum. Appl Biochem Biotechnol. 166, 1843-1855 (2012).

51. Xia, S. et al. Production, characterization, and antioxidant activity of fucoxanthin from the marine diatom Odontella aurita. Mar Drugs. 11, 2667-2681 (2013).

52. Piasecka, A., Cieśla, J., Koczańska, M. \& Krzemińska, I. Effectiveness of Parachlorella kessleri cell disruption evaluated with the use of laser light scattering methods. J. Appl. Phycol. 31, 97-107 (2019).

53. Krzemińska, I., Pawlik-Skowrońska, B., Trzcińska, M. \& Tys, J. Influence of photoperiods on the growth rate and biomass productivity of green microalgae. Bioproc Biosyst Eng. 37, 735-741 (2014).

54. Piasecka, A., Krzemińska, I. \& Tys, J. Physical methods for microalgal biomass pretreatment. Int Agrophys. 28, 341-348 (2014).

55. Lopez, C. V. G. et al. Protein measurements of micro-algal and cyanobacterial biomass. Bioresource Technol. 101, 7587-7591 (2010).

56. Jebsen, C. et al. FTIR spectra of algal species can be used as physiological fingerprints to assess their actual growth potential. Physiol Plant. 146, 427-438 (2012).

57. Stehfest, K., Toepel, J. \& Wilhelm, C. The application of micro-FTIR spectroscopy to analyze nutriment stress-related in biomass composition of phytoplankton algae. Plant Physiol Biochem. 43, 717-726 (2005).

\section{Acknowledgements}

This work was supported in part by the National Science Centre, Poland [Grant No. 2017/25/N/NZ9/01785] in 2018-2021.

\section{Author contributions}

A.P. designed and performed the experiments, analysed and interpreted the data and wrote the manuscript. A.N. took part in analysis and interpretation of FTIR data. D.W. performed G.C. measurements. I.K. took part in designing of the study, analysis and interpretation of data and drafting the article. I.K. revised the article and took responsibility for the integrity of the work. All authors read and approved the final version of manuscript. 


\section{Competing interests}

The authors declare no competing interests.

\section{Additional information}

Correspondence and requests for materials should be addressed to A.P.

Reprints and permissions information is available at www.nature.com/reprints.

Publisher's note Springer Nature remains neutral with regard to jurisdictional claims in published maps and institutional affiliations.

(c) (i) Open Access This article is licensed under a Creative Commons Attribution 4.0 International License, which permits use, sharing, adaptation, distribution and reproduction in any medium or format, as long as you give appropriate credit to the original author(s) and the source, provide a link to the Creative Commons license, and indicate if changes were made. The images or other third party material in this article are included in the article's Creative Commons license, unless indicated otherwise in a credit line to the material. If material is not included in the article's Creative Commons license and your intended use is not permitted by statutory regulation or exceeds the permitted use, you will need to obtain permission directly from the copyright holder. To view a copy of this license, visit http://creativecommons.org/licenses/by/4.0/.

(c) The Author(s) 2020 